\title{
Application of a new model using productivity coupled with hydrothermal factors (PCH) for evaluating net primary productivity of grassland in southern China
}

\author{
Zheng-Guo Sun ${ }^{1}$, Jie Liu ${ }^{2}$, and Hai-Yang Tang ${ }^{1}$ \\ ${ }^{1}$ College of Agro-grassland Science, Nanjing Agricultural University, 1 Weigang, Nanjing, \\ Jiangsu 210095, People's Republic of China \\ ${ }^{2}$ Department of Environmental Science, Hokkaido University, Sapporo 060-0810, Japan
}

Correspondence to: Zheng-Guo Sun (sunzg@njau.edu.cn)

Received: 27 October 2016 - Discussion started: 8 November 2016

Revised: 7 February 2017 - Accepted: 29 March 2017 - Published: 21 April 2017

\begin{abstract}
Grassland ecosystems play important roles in the global carbon cycle. The net primary productivity (NPP) of grassland ecosystems has become the hot spot of terrestrial ecosystems. To simulate grassland NPP in southern China, a new model using productivity coupled with hydrothermal factors $(\mathrm{PCH})$ was built and validated based on data recorded from 2003 to 2014. The results show a logarithmic correlation between grassland NPP and mean annual temperature and a linear positive correlation between grassland NPP and mean annual precipitation in southern China, both highly significant relationships. There was a highly significant correlation between simulated and measured NPP $\left(R^{2}=0.8027\right)$. Both RMSE and relative root mean square error (RRMSE) were relatively low, showing that the simulation results of the model were reliable. The NPP values in the study area had a decreasing trend from east to west and south to north. Mean NPP was $471.62 \mathrm{~g} \mathrm{C} \mathrm{m}^{-2}$ from 2003 to 2014. Additionally, the mean annual NPP of southern grassland presented a rising trend, increasing $3.49 \mathrm{~g} \mathrm{C} \mathrm{m}^{-2} \mathrm{yr}^{-1}$ during the past 12 years. These results document performance and use of a new method to estimate the grassland NPP in southern China.
\end{abstract}

\section{Introduction}

Grassland is one of the major biological communities in the world. It covers more than $40 \%$ of the total land area on the planet and plays an important role in the global biogeo- chemical cycle and energy transformation process (Chen and Zhang, 2000; Mosier et al., 1991). Meanwhile, grassland also plays a role in water and soil conservation, wind breaking and sand fixation, biodiversity maintenance, and shaping soil from surface to depth, and it shows a close connection with human survival and development (Brevik et al., 2015). The root system of grassland vegetation occurs in soil, and thus the direct link between soil and vegetation can be discovered. Most soil functions have strong ties to vegetation, including biomass production; biodiversity pooling; and storing, filtering, and transforming nutrients, substances, and water (Keesstra et al., 2016). In the soil - grassland vegetation - atmosphere continuum, grassland acts as the center of ecological functions on the ecosystem scale. The impacts of the climate on grasslands are quite complicated. On the one hand, different types of grasslands have their own spatial distributions controlled by temperature and precipitation; on the other hand, a rise in temperature will alter some processes in the ecosystem (such as evapotranspiration, decomposition, and photosynthesis). Therefore, temperature exerts a significant effect on biological community productivity (Douglas and Geoffrey, 1997). Net primary productivity (NPP) is an indicator that measures the production capacity and economically and socially significant products of the plant community under natural conditions (Sun et al., 2013). Changes in NPP directly reflect the response of ecosystems to climatic conditions; therefore, it can be used as a research index in the relationship between ecosystem function and climate change (Zhou et al., 2014). It also has an important theoretical and 
practical significance for evaluating the environmental quality of terrestrial ecosystems, regulating ecological processes, and estimating the terrestrial carbon sink to master the interannual variation rule of terrestrial NPP (Cao et al., 2013; Richardson et al., 2012; Picard et al., 2005; Zhang et al., 2011; Xu et al., 2012).

Estimation methods, most based on models, to calculate grassland NPP were discussed in previous research (Gill et al., 2002). Models demonstrate advantages over other methods in global, regional, and other large-scale studies, becoming an important tool in macro-ecological research of grasslands. Grassland NPP estimation models have been used by some researchers for dynamic monitoring and forecasting (Raich et al., 1991; Matsushita and Tamura 2002), providing theoretical and technical support for ecological improvement and recovery of grasslands (Christenson et al., 2014). A large number of studies were conducted by domestic and foreign scholars to understand the influence of climate change on ecosystem processes, including grassland productivity and grassland $\mathrm{C}$ circulation. Although many researchers have studied the influences on a national or regional scale (Parton et al., 1995; Hall et al., 1995; Braswell et al., 1997; Cao and Woodward, 1998; Fang et al., 2001; Ni, 2002; Mantgem and Stephenson, 2007; Wunder et al., 2013; Gang et al., 2015), there has been little research on relationships between grassland NPP and climate factors in southern China. Grassland resources are abundant in China, with an area of nearly 400 million ha, nearly one-sixth of which is in southern China. As the grassland in northern areas continues to deteriorate and become desert, the ecological system of grassy hills and slopes in southern China is becoming increasingly important. Study of the relationship between NPP and climatic factors, together with their dynamic simulation, will provide insights on the effective management and reasonable utilization of grasslands in southern China and the promotion of global change research. Our objectives were the following: (1) to build a model using productivity coupled with hydrothermal factors ( $\mathrm{PCH}$ ) based on the statistical analysis of the relationship between measured NPP, precipitation, and temperature; (2) to modify the adjustment coefficient and the parameter of the model based on the grassland types and their ecological characteristics; (3) to simulate NPP using the PCH model and analyze its changing trends in spatial and temporal patterns from 2003 to 2014; (4) to verify the accuracy of the PCH model by comparing it with field observation data; and (5) to explore the dominant hydrothermal factor for determining the NPP change in the study area.

\section{Materials and methods}

\subsection{Study area}

The grassy hills and slopes of southern China, centered at $110^{\circ} 0^{\prime} \mathrm{E}, 27^{\circ} 30^{\prime} \mathrm{N}$, were the focus of our research. The site

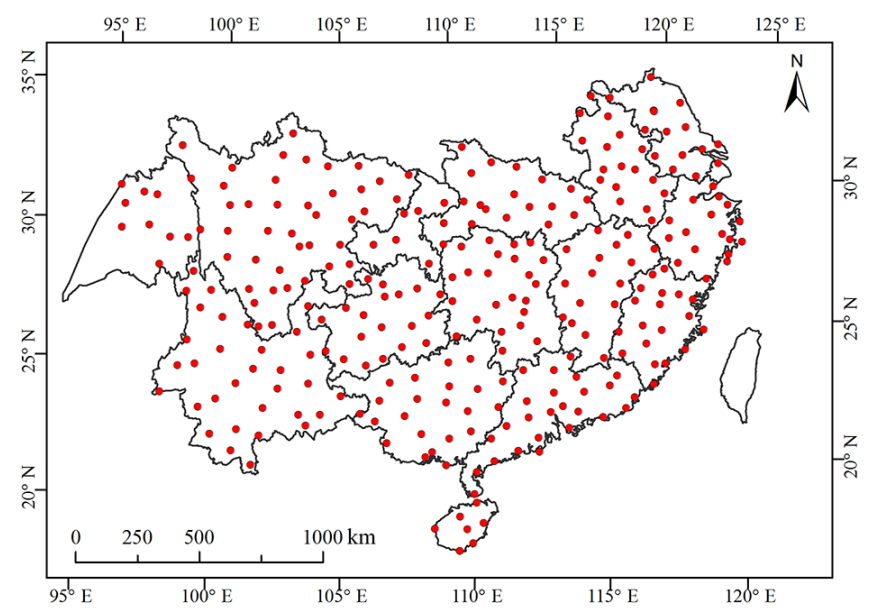

Figure 1. Study area and meteorological stations in southern China (the black boundary lines indicate the provincial boundary; the red dots represent the locations of the meteorological stations).

encompassed 17 provinces and an area of about 60 million ha (Fig. 1). The grasslands of southern China are mainly composed of typical grassland, wetland grassland, lowland meadow, and upland meadow. The southern grasslands are scattered and distributed among areas of forest land and cultivated land and are mostly located on slopes. Most regions of the southern grasslands are managed with grazing and some regions with enclosure and cutting. The climate characteristics in this area include hot and rainy summers and mild and rainy winters, with the frost-free period being more than 300 days per year. The annual mean precipitation is between 800 and $1600 \mathrm{~mm}$ and the annual mean temperature is greater than $15^{\circ} \mathrm{C}$. These climate conditions contribute to a suitable environment for grassland.

\subsection{Data acquirement and processing}

NPP data were acquired in July of 2011, 2012, and 2013, 66 sample plots were investigated in several provinces of the study area. Five quadrats $(1 \mathrm{~m} \times 1 \mathrm{~m})$ were set on corners and in the center of each representative sample plot $(10 \mathrm{~m} \times 10 \mathrm{~m})$. Aboveground biomass and the latitude and longitude information were recorded in each small quadrat, with an average level calculated after sampling. Every $2.2 \mathrm{~g}$ of dry matter was converted into $1 \mathrm{~g}$ carbon, leading to the grass NPP in each sample area, represented in the form of carbon (grams of carbon per square meter) (Fang et al., 2001).

Climate data acquired includes temperature and precipitation data from the years 2003 to 2014 from the ground stations of China Meteorological Data Service center (http: //data.cma.cn/site/index.html) (Fig. 1). Kriging interpolation from the geographic information system (GIS) interpolation tool was utilized to analyze meteorological data according to the latitude and longitude of each station. Then the image 
projection transformation converted data into a raster image with a latitude and longitude network and $1000 \mathrm{~m}$ resolution. Finally, temperature and precipitation information was extracted according to latitude and longitude corresponding to the investigation points.

The 1980 Chinese grassland resource inventory and MOD12Q1 data acquired in 2004 were used to generate the land cover, land use map and the grassland distribution map (Fig. 2). Open shrubs, woody savannas, savannas, grasslands, and permanent wetlands were included as the grassland of southern China based on the land use and land cover classification project proposed by the International GeosphereBiosphere Programme (IGBP).

\subsection{Model establishment and validation}

Based on the statistical analysis of the relationship between measured NPP, precipitation, and temperature, the preliminary structure of the model was developed. Then the nonlinear fitting algorithm was utilized to optimize and determine the parameters of the model.

In order to verify the reliability of the simulation results, both RMSE and relative root mean square errors (RRMSE) were applied to the model for testing and evaluating the simulation effects. RMSE and RRMSE were expressed as

$$
\begin{aligned}
& \text { RMSE }=\sqrt{\frac{1}{n} \sum_{i=1}^{n}\left(O_{i}-S_{i}\right)^{2}} \\
& \text { RRMSE }=\frac{\sqrt{\frac{1}{n} \sum_{i=1}^{n}\left(O_{i}-S_{i}\right)^{2}}}{O_{\mathrm{a}}},
\end{aligned}
$$

where $O_{i}$ was the real value, $S_{i}$ was the simulated value, $O_{\text {a }}$ was the average of real value, and $n$ was the total number of samples.

\section{Results}

\subsection{Relationship between grassland NPP and temperature}

Grassland NPP is a joint result of the regional light, temperature, precipitation, soil, and other natural conditions, which reflects the ability of using natural environmental resources (Gang et al., 2015). Under natural conditions, temperature and precipitation were the two dominate influential factors in grassland NPP in southern China (Sun et al., 2014). The results of the analysis of the relationship between grassland NPP and temperature in southern China showed that (1) between 10 and $20^{\circ} \mathrm{C}$ there was a linear positive correlation between temperature and the NPP and (2) a para-curve relationship was found between 20 and $30^{\circ} \mathrm{C}$. Generally, the relationship between temperature and grassland NPP was

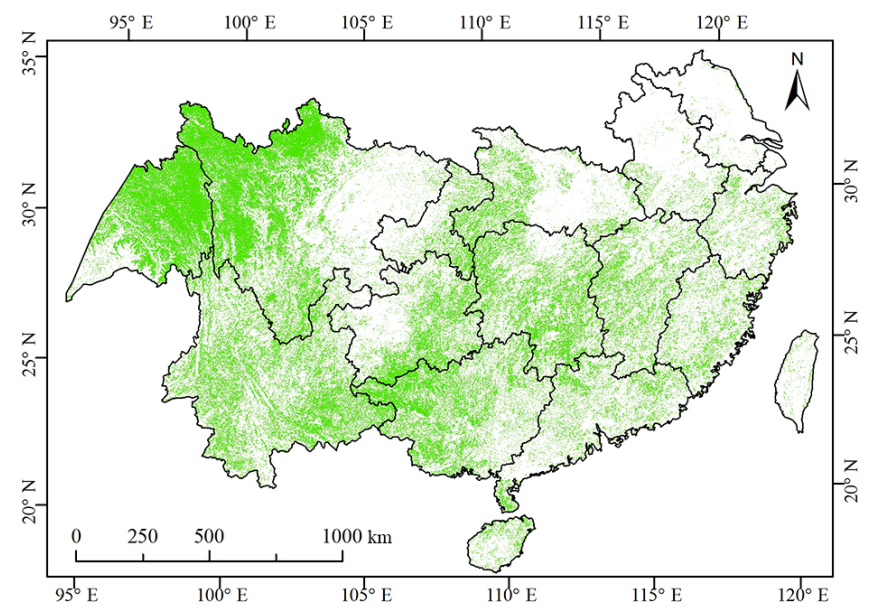

Figure 2. The distribution map of grasslands of southern China (the black boundary lines indicate the provincial boundary, the green zone represents the grassland area, and the colorless region represents non-grassland in the study area).

logarithmic, with correlation coefficient $r$ being 0.4629 and reaching a significant level $(P<0.01)$. As a result, the relationship could be presented as a logarithmic equation.

\subsection{Relationship between grassland NPP and precipitation}

Precipitation is a key factor in many NPP estimation models (Huston, 2012; Yu et al., 2008). Mean monthly precipitation in the grassland ecological system of southern China presented a large range throughout a year, with minimum precipitation being $40 \mathrm{~mm}$ and the maximum being over $200 \mathrm{~mm}$. NPP also showed a regular distribution according to the precipitation, with a typical linear positive correlation. The correlation coefficient $r$ was 0.7836 , reaching a very significant level $(P<0.01)$. Therefore, the influences of precipitation on grassland NPP could be expressed as a linear equation.

\subsection{Estimation model of grassland NPP}

\subsubsection{Model establishment}

According to the analysis results, a positive relationship existed between grassland NPP and mean annual temperature and annual precipitation in southern China. Thus, it is feasible to express the relationship with logarithmic and linear equations, respectively. However, the results varied greatly when temperature was directly used as the equation factor and any data below $0{ }^{\circ} \mathrm{C}$ failed to be processed. Thus, it was necessary to introduce a temperature adjustment coefficient, described here as

$$
T_{a}=\operatorname{Ln}\left(\frac{T}{t_{1}}+a_{1}\right)
$$


where $T_{\mathrm{a}}$ was the temperature adjustment coefficient, $T$ was the mean annual temperature $\left({ }^{\circ} \mathrm{C}\right), t_{1}$ was the model parameter, and $a_{1}$ was a constant, set to 2.5 in the paper.

Precipitation showed a similar trend. Growth stopped when moisture was below a certain level. Thus, another adjustment coefficient was introduced and expressed as the following:

$$
W_{\mathrm{a}}=\operatorname{Sqrt}\left(\frac{W}{w_{1}}+a_{2}\right),
$$

where $W_{\mathrm{a}}$ was the adjustment coefficient, $W$ was the mean annual precipitation $(\mathrm{mm}), w_{1}$ was the model parameter, and $a_{2}$ was a constant, set to 0.5 in the paper.

According to the information above, the estimation model of grassland NPP in southern China could be written as the following:

$\mathrm{NPP}=T_{\mathrm{a}} \times W_{\mathrm{a}} \times\left(T+\frac{W}{6}\right)$.

The PCH model was built to simulate grassland NPP of southern China based on the principle of grassland productivity coupled with hydrothermal factors. In order to improve the applicability in the grassland of southern China and the accuracy of the simulation results, adjustment coefficients related to temperature and precipitation were introduced into the model. Though the PCH model has not been applied to simulate the NPP of different types of vegetation, the establishment and application of the model were based on the specific spatial distribution of grassland and the complicated hydrothermal conditions in southern China. Each model has its advantages and limitations depending on different study targets and scales. The limitation of the model is that fewer influential factors were introduced into the model compared with other ecological models. The future analysis and explication of this will be carried out in the discussion part of this paper. The strength of the PCH model lies in the origin of the model establishment and the focalization and directness of assessing the NPP of grassland in southern China. The novelty of this model is mainly embodied in the process of hydrothermal assimilation in comparison to other models. Understanding controls over NPP will be crucial in developing models of these processes at larger spatial scales. Thus, the $\mathrm{PCH}$ model combines the hydrothermal parameter and ecosystem process approach to quantify the carbon flow of grassland in southern China (Gill et al., 2002).

\subsubsection{Calculation of model parameters}

The acquisition of model parameters was a complicated process and would directly affect the accuracy of the final results. Based on the measured data from 2009 to 2010, by adopting the contraction expansion algorithm of the nonlinear fitting and MATLAB programs (Conway and Wilcox, 1970), those parameters were calculated as $t_{1}=5.8$ and $w_{1}=560.4$.

\subsubsection{Model validation}

The measured grassland NPP data from 2014 in southern China were used to validate the simulation results. The results indicated that there was a strong and significant correlation between the simulated and measured NPP $\left(R^{2}=0.802\right.$, $P<0.01)$. The RMSE of the simulation was $58.351 \mathrm{~g} \mathrm{C} \mathrm{m}^{-2}$, the RRMSE was 0.326 , and both were small. All these results indicate that the simulation of precipitation and temperature model for southern grassland NPP was feasible. The trends of the simulated and measured grassland NPP were similar (Fig. 3), which also indicated that the results were reliable.

\subsection{Spatiotemporal variations of grassland NPP from the years 2003 to 2014}

The spatial distribution map of grassland NPP produced by the estimation model was beneficial in monitoring the grassland resource. This paper built the spatial distribution map of southern grassland NPP using the estimation model of grassland NPP based on climatic conditions (Fig. 4). It showed that the minimum of mean annual NPP of southern grassland was $57.83 \mathrm{~g} \mathrm{C} \mathrm{m}^{-2}$ and the maximum was $1328.06 \mathrm{~g} \mathrm{C} \mathrm{m}^{-2}$ in the last 12 years. The NPP of southern grassland had an obvious zonal distribution. The NPP value was lower in northwestern regions and higher in southeastern and southern regions, especially in Jiangxi, Guangdong, and Hainan provinces.

The variation of mean annual NPP and the relevant statistical indices of southern grassland in the last 12 years were shown in Fig. 5. The trend of mean annual NPP presented an increasing tendency of the whole southern grassland from 2003 to 2014. The variation range of the mean annual NPP was from 430.31 to $519.82 \mathrm{~g} \mathrm{C} \mathrm{m}^{-2}$, and the mean was $471.62 \mathrm{~g} \mathrm{C} \mathrm{m}^{-2}$. The minimum of the mean annual NPP appeared in 2006, and the maximum value appeared in 2013. The tilt rate of the mean annual NPP of southern grassland in the last 12 years was $3.49 \mathrm{~g} \mathrm{C} \mathrm{m}^{-2} \mathrm{yr}^{-1}$, which indicated that the NPP increased about $3.49 \mathrm{~g} \mathrm{C} \mathrm{m}^{-2}$ every year $(P<0.05)$.

\section{Discussion}

The parameters of the model were set to mediate the abnormal values from the model inputs and thus keep the stability of the model results. They were determined and constrained using multi-observation results. Hence, the model parameters are not associated with specific grassland types or the corresponding ecological characteristics. To incorporate remote sensing information into this model, we propose applying a remote sensing dataset as a spatially explicit scalar for the model parameterization, and thus enhancing the prediction ability of the future version of the model.

Research on the relationships between the NPP and climate factors in global or regional ecological systems started in the mid-1800s (Nemani et al., 2003; Zhou et al., 2014). As 


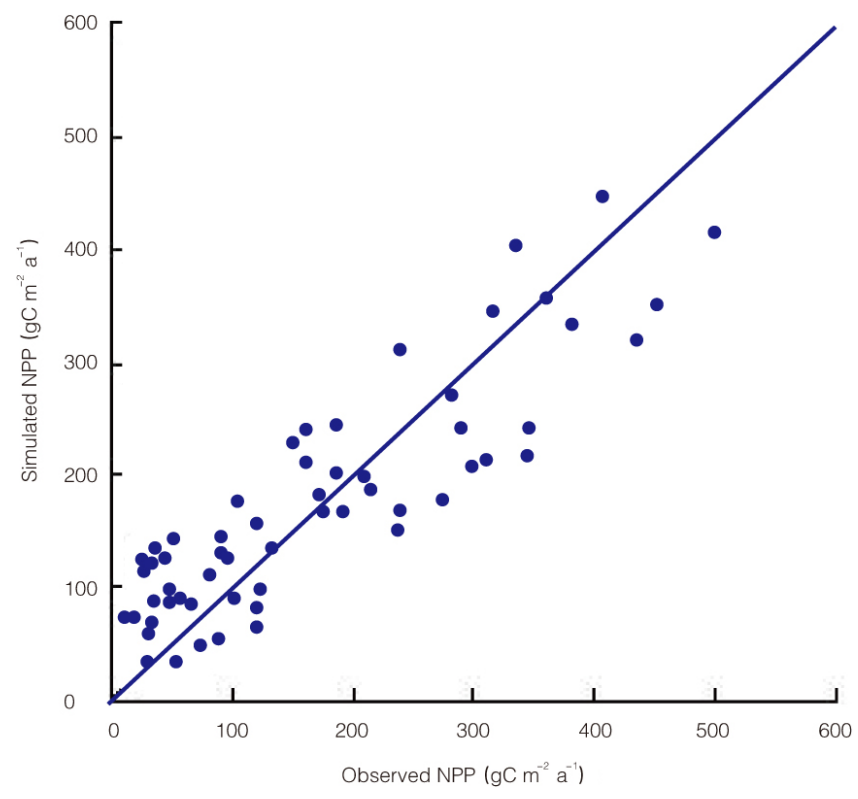

Figure 3. Comparison between simulated and observed grassland NPP (net primary productivity) in southern China.

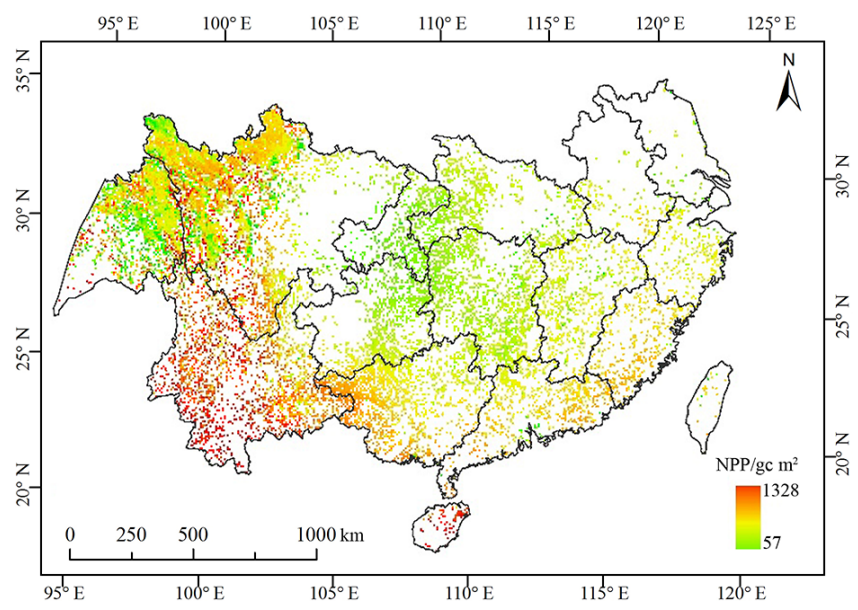

Figure 4. Spatial characteristics of grassland NPP in southern China from 2003 to 2014.

revealed in these studies, the vegetation index showed periodic variations with corresponding climate indices, including temperature and precipitation, during the growth process of most plants. Temporal and spatial variations were quite distinct in grassland NPP, since climatic factors, especially precipitation and temperature, were factors directly linked to periodic variations (Ronnenberg and Wesche, 2010). This study showed that a temperature rise would cause a certain level of rise in the grassland NPP in southern China, especially in the high-temperature zones. However, these results differed from some previous reports (Mcguire et al., 1993). In addition, there was a significant positive correlation between precipitation and NPP. When mean annual precipitation increases,

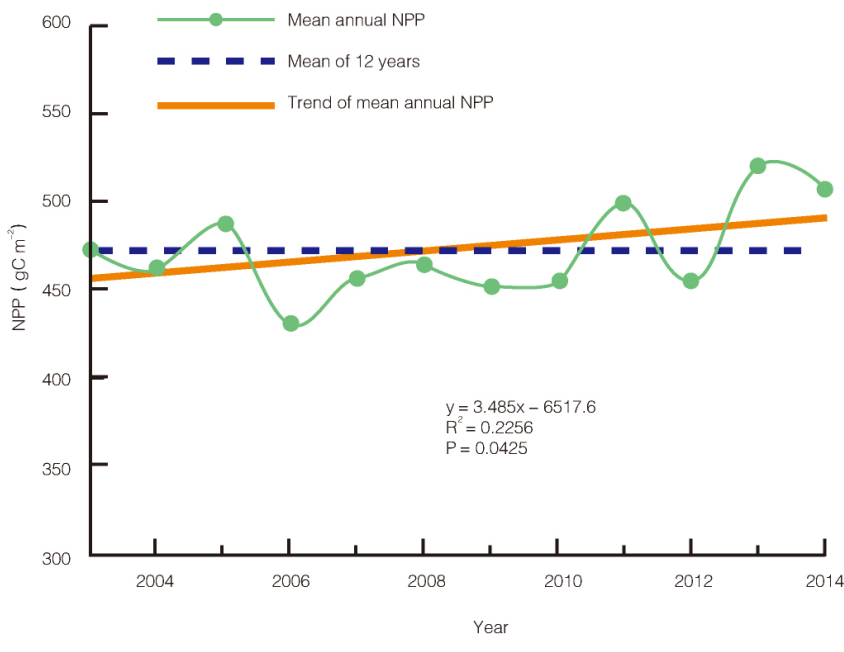

Figure 5. The interannual variation of grassland NPP in southern China from 2003 to 2014.

grassland NPP would also increase significantly. This conclusion is consistent with previous studies (Sala et al., 2000; Knapp and Smith, 2001; Mohamed et al., 2004).

The ultimate goal of those studies regarding the relationship between climate and terrestrial ecosystem NPP is to predict the possible impacts on climate change and to take scientific countermeasures (Pablo et al., 2007), and establishing a model is an efficient means to make these predictions. Through modeling and simulation, one could reveal the quantitative change and trend of NPP caused by climate change. That was why the research of the NPP model attracted a vast amount of attention (Ren et al., 2011). This study establishes an estimation model for the grassland NPP in southern China by using the statistical analysis of the relationship between the southern grassland NPP and precipitation and temperature, combined with biological process. The relationship between simulated and observed values reached a highly significant level. This and the low RMSE validated the reliability of the model. Therefore, it was feasible to estimate the grassland NPP in southern China by using the PCH model described in this paper.

The estimation of grassland NPP is a complex process. It is not only affected by climatic factors such as precipitation and temperature but also by the grassland vegetation's own inner physiological processes, fire severity, slope position and aspect, grazing, human activities, cutting frequency, and grassland ecotypes (Pereira et al., 2016; Shaw et al., 2016; Lu et al., 2015; Lin et al., 2015; Poeplau et al., 2016; Roosendaal et al., 2016).

Grassy hills and slopes in southern China had a wide distribution with various vegetation types; therefore, the NPP distribution was uneven. Although the model estimation worked well, some imperfections exist. Firstly, a classification for grass hills and slopes is needed, without which the NPP estimation fell into a single type (Hu et al., 2016). Secondly, 
the NPP estimation results were representative of the entire year, while arbitrary NPP estimation for a single month has not been verified yet. Thirdly, as an important ecological parameter, the MODIS normalized difference vegetation index needs to be added into the model (Gong et al., 2015). Then precision of the model could be improved in the process of evaluating the changes of grassland in southern China. Fourth, grassland soil coarseness needs to be taken into account as a result of nutrient cycling and respiration in grassland (Lü et al., 2016). The last issue concerns sensitivity. The study indicated that the simulation results from the PCH model were large in a small fraction of areas with relatively low NPP, while they were small in an area with high NPP. This may be caused by the limited time span and other factors, including the influences from different types of grasslands. Hence, there might be some uncertainty in estimating the lower or higher grassland NPP using the estimation model. Further study is required to solve these problems.

\section{Conclusion}

In this study, a new model using productivity coupled with hydrothermal factors $(\mathrm{PCH})$ was built to simulate the NPP in southern China's grasslands. The PCH model uses productivity coupled with hydrothermal factors that can be expressed by the transformation of the model parameters, mean annual temperature and mean annual precipitation, which are the two most critical factors affecting the NPP of southern China's grasslands. The results show that there is a logarithmic correlation between grassland NPP and mean annual temperature, and there is a linear positive correlation between grassland NPP and mean annual precipitation in southern China. There was a very significant correlation between simulated and measured NPP $\left(R^{2}=0.8027\right)$. Meanwhile, both RMSE and RRMSE stayed at a relatively low level, showing that the simulation results of the model were reliable. The NPP values in the study area had a decreasing trend from east to west and south to north. The mean NPP was $471.62 \mathrm{~g} \mathrm{C} \mathrm{m}^{-2}$ from 2003 to 2014 . Additionally, the mean annual NPP of southern grassland presented a rising trend and the rate of change was $3.49 \mathrm{~g} \mathrm{C} \mathrm{m}^{-2} \mathrm{yr}^{-1}$ in the last 12 years.

Data availability. The observation data from the sample plots in the study area were collected by Zheng-Guo Sun and his graduates. The hydrothermal data, including temperature and precipitation, were downloaded from the ground stations of the China Meteorological Data Service center (http://data.cma. cn/site/index.html). The Arc GIS 10.4.1 software was downloaded from the website http://www.esri.com/en/arcgis/products/ arcgis-pro/overview. The authors declare that all data used in this paper are authentic and credible. The data of this study can be provided by the authors upon request.
Competing interests. The authors declare that they have no conflict of interest.

Acknowledgements. We are grateful to the chief editor and anonymous reviewers for their illuminating comments. We would also like to thank Kenneth A. Albrecht (Department of Agronomy, University of Wisconsin-Madison, WI 53706, USA) for his helpful comments on the draft of this paper. This work was supported by the project of Natural Science Fund of Jiangsu Province (BK20140413) and the Key Project of the Chinese National Programs for Fundamental Research and Development (973 Program, 2010CB950702).

Edited by: A. Jordán

Reviewed by: five anonymous referees

\section{References}

Braswell, B. H., Schimel, D. S., Linder, E., and Moore III., B.: The response of global terrestrial ecosystems to interannual temperature variability, Science, 278, 870-872, doi:10.1126/science.278.5339.870, 1997.

Brevik, E. C., Cerdà, A., Mataix-Solera, J., Pereg, L., Quinton, J. N., Six, J., and Van Oost, K.: The interdisciplinary nature of SOIL, SOIL, 1, 117-129, doi:10.5194/soil-1-117-2015, 2015.

Cao, L., Xu, J., Chen, Y., Li, W., Yang, Y., Hong, Y., and Li, Z.: Understanding the dynamic coupling between vegetation cover and climatic factors in a semiarid region-a case study of Inner Mongolia, China, Ecohydrology, 6, 917-926, doi:10.1002/eco.1245, 2013.

Cao, M. K. and Woodward, F. I.: Dynamic responses of terrestrial ecosystem carbon cycling to global climate change, Nature, 393, 249-252, doi:10.1038/30460, 1998.

Chen, Z. X. and Zhang, X. S.: Value of ecosystem services in China, Chinese Sci. Bull., 45, 17-22, doi:10.1007/BF02886190, 2000.

Christenson, L. M., Mitchell, M. J., Groffman, P. M., and Lovett, G. M.: Cascading effects of climate change on forest ecosystems: biogeochemical links between trees and moose in the northeast USA, Ecosystems, 3, 1-16, doi:10.1007/s10021-013-9733$5,2014$.

Conway, G. R. and Wilcox, J. C.: Fitting nonlinear models to biological data by Marquardt's algorithm, Ecology, 3, 503-507, doi:10.2307/1935386, 1970.

Douglas, G. G. and Geoffrey, M. H.: A technique for monitoring ecological disturbance in tall grass prairie using seasonal NDVI trajectories and a discriminate function mixture model, Remote Sens. Environ., 61, 270-278, doi:10.1016/S00344257(97)00043-6, 1997.

Fang, J. Y., Chen, A. P., Peng, C. H., Zhao, S. Q., and Ci, L. J.: Changes in forest biomass carbon storage in China between 1949 and 1998, Science, 292, 2320-2322, doi:10.1126/science.1058629, 2001.

Gang, C., Zhou, W., Wang, Z., Chen, Y., Li, J., Chen, J., Qi, J., Odeh, I., and Groisman, P. Y.: Comparative Assessment of Grassland NPP Dynamics in Response to Climate Change in China, North America, Europe and Australia from 1981 to 2010, J. Agron. Crop Sci., 1, 57-68, doi:10.1111/jac.12088, 2015. 
Gill, R. A., Kelly, R. H., Parton, W. J., Day, K. A., Jackson, R. B., Morgan, J. A., Scurlock, J. M. O., Tieszen, L. L., Castle, J. V., Ojima, D. S., and Zhang, X. S.: Using simple environmental variables to estimate below-ground productivity in grasslands, Global Ecol. Biogeogr., 1, 79-86, doi:10.1046/j.1466822X.2001.00267.x, 2002.

Gong, Z., Kawamura, K., Ishikawa, N., Goto, M., Wulan, T., Alateng, D., Yin, T., and Ito, Y.: MODIS normalized difference vegetation index (NDVI) and vegetation phenology dynamics in the Inner Mongolia grassland, Solid Earth, 6, 1185-1194, doi:10.5194/se-6-1185-2015, 2015.

Hall, D. O., Ojima, D. S., Parton, W. J., and Scurlock, J. M. O.: Response of Temperate and Tropical Grasslands to $\mathrm{CO}_{2}$ and Climate Change, J. Biogeogr., 22, 537-547, doi:10.2307/2845952, 1995.

Hu, G., Liu, H., Yin, Y., and Song, Z.: The Role of Legumes in Plant Community Succession of Degraded Grasslands in Northern China, Land Degrad. Dev., 27, 366-372, doi:10.1002/ldr.2382, 2016.

Huston, M. A.: Precipitation, soils, NPP, and biodiversity: resurrection of albrecht's curve, Ecol. Monogr., 3, 277-296, doi:10.1890/11-1927.1, 2012.

Keesstra, S. D., Bouma, J., Wallinga, J., Tittonell, P., Smith, P., Cerdà, A., Montanarella, L., Quinton, J. N., Pachepsky, Y., van der Putten, W. H., Bardgett, R. D., Moolenaar, S., Mol, G., Jansen, B., and Fresco, L. O.: The significance of soils and soil science towards realization of the United Nations Sustainable Development Goals, SOIL, 2, 111-128, doi:10.5194/soil-2-1112016, 2016.

Knapp, A. K. and Smith, M. D.: Variation among biomes in temporal dynamics of aboveground primary production, Science, 291, 481-484, doi:10.1126/science.291.5503.481, 2001.

Lin, L., Li, Y. K., Xu, X. L., Zhang, F. W., Du, Y. G., Liu, S. L., Guo, X. W., and Cao, G. M.: Predicting parameters of degradation succession processes of Tibetan Kobresia grasslands, Solid Earth, 6, 1237-1246, doi:10.5194/se-6-1237-2015, 2015.

Lü, L., Wang, R., Liu, H., Yin, J., Xiao, J., Wang, Z., Zhao, Y., Yu, G., Han, X., and Jiang, Y.: Effect of soil coarseness on soil base cations and available micronutrients in a semi-arid sandy grassland, Solid Earth, 7, 549-556, doi:10.5194/se-7-549-2016, 2016.

Lu, X., Yan, Y., Sun, J., Zhang, X., Chen, Y., Wang, X., and Cheng, G.: Short-term grazing exclusion has no impact on soil properties and nutrients of degraded alpine grassland in Tibet, China, Solid Earth, 6, 1195-1205, doi:10.5194/se-6-1195-2015, 2015.

Mantgem, P. J. V. and Stephenson, N. L.: Apparent climatically induced increase of tree mortality rates in a temperate forest, Ecol. Lett., 10, 909-916, doi:10.1111/j.14610248.2007.01080.x, 2007.

Matsushita, B. and Tamura, M.: Integrating remotely sensed data with an ecosystem model to estimate net primary productivity in East Asia, Remote Sens. Environ., 81, 58-66, doi:10.1016/S0034-4257(01)00331-5, 2002.

Mcguire, A. D., Joyce, L. A., Kicklighter, D. W., Melillo, J. M., Esser, G., and Vorosmarty, C. J.: Productivity response of climax temperate forests to elevated temperature and carbon dioxide: a North American comparison between two global models, Climatic Change, 4, 287-310, doi:10.1007/BF01091852, 1993.
Mohamed, M. A., Babiker, I. S., Chen, Z. M., Ikeda, K., Ohta, K., and Kato, K.: The role of climate variability in the inter-annual variation of terrestrial net primary production (NPP), Sci. Total Environ., 332, 123-137, doi:10.1016/j.scitotenv.2004.03.009, 2004.

Mosier, A. R., Schimel, D., Valentine, D., Bronson, K., and Parton, W.: Methane and nitrous oxide fluxes in native, fertilized and cultivated grasslands, Nature, 350, 330-332, doi:10.1038/350330a0, 1991.

Nemani, R. R., Keeling, C. D., Hashimoto, H., Jolly, W. M., Piper, S. C., Tucker, C. J., Myneni, R. B., and Running, S. W.: Climate-driven increases in global terrestrial net primary production from 1982 to 1999 , Science, 300, 1560-1563, doi:10.1126/science.1082750, 2003.

$\mathrm{Ni}$, J.: Effects of climate change on carbon storage in boreal forests of china: a local perspective, Climatic Change, 1-2, 61-75, doi:10.1023/A:1020291220673, 2002.

Pablo, M., Thomas, H., David, P. R., Benjamin, S., and Martin, T. S.: Changes in European ecosystem productivity and carbon balance driven by regional climate model output, Glob. Change Biol., 1, 108-122, doi:10.1111/j.1365-2486.2006.01289.x, 2007.

Parton, W. J., Scurlock, J. M. O., Ojima, D. S., Schimel, D. S., and Hall, D. O.: Impact of climate change on grassland production and soil carbon worldwide, Glob. Change Biol., 1, 13-22, doi:10.1111/j.1365-2486.1995.tb00002.x, 1995.

Pereira, P., Cerdà, A., Lopez, A. J., Zavala, L. M., Mataix-Solera, J., Arcenegui, V., Misiune, I., Keesstra, S., and Novara, A.: Shortterm vegetation recovery after a grassland fire in Lithuania: the effects of fire severity, slope position and aspect, Land Degrad. Dev., 27, 1523-1534, doi:10.1002/ldr.2498, 2016.

Picard, G., Quegan, S. N., Lomas, M. R., Toan, T. L., and Woodward, F. I.: Bud-burst modelling in Siberia and its impact on quantifying the carbon budget, Glob. Change Biol., 12, 2164 2176, doi:10.1111/j.1365-2486.2005.01055.x, 2005.

Poeplau, C., Marstorp, H., Thored, K., and Kätterer, T.: Effect of grassland cutting frequency on soil carbon storage - a case study on public lawns in three Swedish cities, SOIL, 2, 175-184, doi:10.5194/soil-2-175-2016, 2016.

Raich, J. W., Rastetter, E. B., Melillo, J. M., Kicklighter, D. W., and Steudler, P. B. J.: Potential net primary productivity in South America: application of a global model, Ecol. Appl., 4, 399-429, doi:10.2307/1941899, 1991.

Ren, W., Tian, H., Tao, B., Chappelka, A., Sun, G., Lu, C., Liu, M., Chen, G., and $\mathrm{Xu}, \mathrm{X}$.: Impacts of tropospheric ozone and climate change on net primary productivity and net carbon exchange of china's forest ecosystems, Global Ecol. Biogeogr., 3, 391-406, doi:10.1111/j.1466-8238.2010.00606.x, 2011.

Richardson, A. D., Anderson, R. S., Arain, M. A., Barr, A. G., Bohrer, G., and Chen, G.: Terrestrial biosphere models need better representation of vegetation phenology: results from the north American carbon program site synthesis, Glob. Change Biol., 2, 566-584, doi:10.1111/j.1365-2486.2011.02562.x, 2012.

Ronnenberg, K. and Wesche, K.: Effects of fertilization and irrigation on productivity, plant nutrient contents and soil nutrients in Southern Mongolia, Plant Soil, 1-2, 239-251, doi:10.1007/s11104-010-0409-z, 2010.

Roosendaal, D., Stewart, C. E., Denef, K., Follett, R. F., Pruessner, E., Comas, L. H., Varvel, G. E., Saathoff, A., Palmer, N., Sarath, G., Jin, V. L., Schmer, M., and Soundararajan, M.: Switchgrass 
ecotypes alter microbial contribution to deep-soil C, SOIL, 2, 185-197, doi:10.5194/soil-2-185-2016, 2016.

Sala, O. E., Chapin III., F. S., Armesto, J. J., Berlow, E., Bloomfield, J., Dirzo, R., Huber-Sanwald, E., Huenneke, L. F., Jackson, R. B., Kinzig, A., Leemans, R., Lodge, D. M., Mooney, H. A., Oesterheld, M., Poff, N. L., Syke, M. T., Walker, B. H., Walker, M., and Wall, D. H.: Global biodiversity scenarios for the year 2100, Science, 287, 1770-1774, doi:10.1126/science.287.5459.1770, 2000 .

Shaw, E. A., Denef, K., Milano de Tomasel, C., Cotrufo, M. F., and Wall, D. H.: Fire affects root decomposition, soil food web structure, and carbon flow in tallgrass prairie, SOIL, 2, 199-210, doi:10.5194/soil-2-199-2016, 2016.

Sun, Z. G., Long, X. H., Sun, C. M., Zhou, W., Ju, W. M., and Li, J. L.: Evaluation of net primary productivity and its spatial and temporal patterns in Southern China's grasslands, Rangeland J., 3, 331-338, doi:10.1071/RJ12061, 2013.

Sun, Z. G., Sun, C. M., Zhou, W., Ju, W. M., and Li, J. L.: Classification and Net Primary Productivity of the Southern China's Grasslands Ecosystem Based on Improved Comprehensive and Sequential Classification System (CSCS) Approach, J. Integr. Agr., 4, 893-903, doi:10.1016/S2095-3119(13)60415-3, 2014.

Wunder, J., Fowler, A. M., Cook, E. R., Pirie, M., and Mccloskey, S. P. J.: On the influence of tree size on the climate-growth relationship of New Zealand Kauri (Agathis australis): insights from annual, monthly and daily growth patterns, Trees, 4, 937-948, doi:10.1007/s00468-013-0846-4, 2013.
Xu, X., Niu, S. L., Sherry, R. A., Zhou, X. H., Zhou, J. Z., and Luo, Y. Q.: Interannual variability in responses of belowground net primary productivity (NPP) and NPP partitioning to long-term warming and clipping in a tall grass prairie, Glob. Change Biol., 18, 1648-1656, doi:10.1111/j.1365-2486.2012.02651.x, 2012.

Yu, D., Zhu, W., and Pan, Y.: The role of atmospheric circulation system playing in coupling relationship between spring NPP and precipitation in East Asia area, Environ. Monit. Assess., 1-3, 135-143, doi:10.1007/s10661-007-0023-6, 2008.

Zhang, G. G., Kang, Y. M., Han, G. D., and Sakurai, K.: Effect of climate change over the past half century on the distribution, extent and NPP of ecosystems of Inner Mongolia, Glob. Change Biol., 17, 377-389, doi:10.1111/j.13652486.2010.02237.x, 2011.

Zhou, W., Gang, C., Zhou, L., Chen, Y., Li, J., Ju, W., and Odeh, I.: Dynamic of grassland vegetation degradation and its quantitative assessment in the northwest China, Acta Oecol., 55, 86-96, doi:10.1016/j.actao.2013.12.006, 2014. 